\title{
TEATRO EN TRANSICIÓN. DRAMATURGIA, POLÍTICA Y RELACIONES SOCIALES EN SANTA FE (ARGENTINA), ENTRE LA ÚLTIMA DICTADURA Y LA TRANSICIÓN DEMOCRÁTICA
}

\author{
TEATRO EM TRANSIÇÃO.DRAMATURGIA, POLÍTICA E RELAÇÕES \\ SOCIAIS EM SANTA FE (ARGENTINA), ENTRE A ÚLTIMA DITADURA \\ E A TRANSIÇÃO DEMOCRÁTICA
}

\author{
Luciano Alonso \\ CESIL, FHUC-UNL / IHUCSO, UNL-CONICET*
}

\section{Resumen}

En el estudio de los fenómenos artísticos y literarios durante la última dictadura cívico-militar argentina (1976-1983), se ha pasado del predominio de una interpretación asentada en la noción de un "apagón cultural" provocado por la represión y la censura, a la consideración de una cierta "resistencia cultural". Por otra parte, la historiografía sobre las actitudes sociales frente a las dictaduras ha mostrado la existencia de amplias "zonas grises" y la inextricable combinación de consensos y disidencias. Este texto se focaliza en los desarrollos del "teatro independiente" santafesino desde el momento central de la dictadura hasta la transición democrática. Presentando una caracterización general del espacio teatral y la postulación de una "comunidad" conformada en torno a determinadas relaciones sociales, se hace foco luego en algunos episodios que permitan un análisis más denso. Se muestra cómo coexistieron algunas actitudes de integración en el marco institucional dictatorial con otras de resistencia micropolítica y de expresión de una subjetividad disidente. Por fin, se postula que la transformación de esas relaciones en términos de transición política, fue de la mano de una transición generacional y estética en la construcción de una nueva dramaturgia.

Palabras clave: Dictadura cívico-militar. Teatro independiente. Integración. Resistencia. Transición. 


\section{Resumo}

No estudo dos fenômenos artísticos e literários durante a última ditadura cívico-militar argentina (1976 -1983), tem passado pelo predomínio de uma interpretação baseada na noção de "apagão cultural" provocado pela repressão e censura, prevalendo, a consideração de uma certa "resistência cultural". Por outro lado, a historiografia sobre as atitudes sociais frente às ditaduras tem mostrado a existência de amplas "zonas cinzentas" e a inextricável combinação de consentimentos e dissidências. Este texto enfoca o desenvolvimento do "teatro independente" santafesino, a partir do momento central da ditadura até a transição democrática. Apresentando uma caracterização geral do espaço teatral e a postulação de uma "comunidade" formada em torno de certas relações sociais, o texto enfoca alguns episódios que permitem uma análise mais densa. Demonstra a coexistência de atitudes de integração no quadro institucional ditatorial com outras de resistência micropolítica e de expressão de uma subjetividade dissidente. Finalmente, postula que a transformação dessas relações em termos de transição política, era da mão de uma transição geracional e estética na construção de uma nova dramaturgia.

Palavras-chave: Ditadura cívico-militar. Teatro independente. Integração. Resistência. Transição.

\section{El campo cultural santafesino a mediados de los años de 1970 y el problema de la "resistencia cultural"}

La identificación hacia la década de 1970 de un "campo cultural santafesino" recortado sobre los desarrollos de las artes y las letras es inevitablemente parcial, pero necesaria para delimitar historiográficamente un objeto. Si puede conceptuarse a la cultura como un modo de lucha por el sentido o “...una forma de interpelación de (y de acceso a) la polis: vale decir, una forma de intervención en el espacio público que construye, de-construye y re-construye identidades sociales y sus posiciones relativas de poder" (GRÜNER, 1990-1991, p. 163; sobre la función de la cultura Grüner, 2002, p. 58-59), los espacios sociales de la cultura pueden concebirse como ámbitos de conflictos desiguales en los cuales los distintos agentes redefinen constantemente su propia identidad e interpelan a otros. Y si lo que llamamos las "artes" y las actividades "intelectuales” en general son todavía un aspecto importante para la definición del 
campo, no es porque sean el reducto de "lo cultural", sino porque -como otros fenómenosrepresentan y vehiculizan sentidos sociales.

Suele suceder que un espacio social coincida con un espacio geográfico (BOURDIEU, 1977) y en este caso se privilegia la identificación de actividades culturales en el ámbito céntrico o "entre bulevares" de la ciudad de Santa Fe ${ }^{\mathrm{i}}$. Sesgada entonces sociogeográficamente la mirada, este espacio aparecía (aparece aun hoy) ocupado por las clases medias y las clases propietarias. En él las clases populares intervenían constantemente, pero con cierta "exterioridad interna": se encontraban en uno u otro ámbito de actividades culturales, se desempeñaban en oficios vinculados a esas acciones, pero no participaban plenamente de ellas, que eran pensadas con las lógicas de las clases medias y propietarias.

Para una caracterización general de ese campo cultural es inevitable reconocer la impronta del diario El Litoral. El vespertino local constituía sin dudas el medio de comunicación hegemónico (PISARELLO, 2013). Su capacidad de influir en la dinámica cultural y representar acabadamente las actividades "entre bulevares", era correlativa a su aptitud para dar cuenta de variadas líneas de pensamiento y propuestas culturales, más allá de los vaivenes de su línea editorialii. En ningún momento de los años '70 o incluso más adelante, El Litoral dejó de ser un medio de comunicación socialmente reconocido y de peso político, a tal punto que sus intervenciones sobre asuntos públicos suponían una suerte de interlocución con las autoridades de turno (véase v. g. CITRONI, 2013).

Hacia mediados de los años de 1970 en la ciudad de Santa Fe y sus cercanías no se contaba con muchos emprendimientos culturales comerciales. Las excepciones estaban dadas por el periódico citado (con la competencia secundaria del Nuevo Diario hasta febrero de 1976), los cines (unas 14 salas contando la de la vecina ciudad de Santo Tomé, a las que podían sumarse otras instituciones en las que se proyectaban filmes en ocasiones especiales), una radio de amplitud modulada (LT9, pues LT10 y LT14 eran y son las radios universitaria y nacional, respectivamente) y el Canal 13 de televisión, de escasa producción local. En el rubro comercial también habría que incluir algunas expresiones de música tropical, folklórica y muy parcialmente rock\&pop, y los corsos y bailes de carnaval, todas actividades que también tenían una amplia faceta vocacional ${ }^{\mathrm{iii}}$.

La mayor parte de las actividades culturales de la zona santafesina del período estaban vinculadas a colectivos vocacionales, asociaciones civiles e incluso a la organización estatal. Precisamente las agencias estatales del orden provincial y municipal tenían una importante 
participación en la generación y sostenimiento de actividades culturales. La impronta de la gestión pública era muy fuerte en el sostenimiento de conjuntos de música clásica y coral, de los festivales folklóricos, de salas de exposición y de premios en artes plásticas, de concursos literarios y ensayísticos y del funcionamiento rutinario de organismos como museos y departamentos especializados. Vinculadas a estas agencias hay que considerar a las instituciones educativas, ya que tanto en ellas como en sus márgenes -grupos de afinidad, asociaciones cooperadoras o de amigos, grupos barriales- se gestaban acciones culturales de todo tipo ${ }^{\text {iv }}$.

La importancia de la esfera estatal en la promoción y organización de la cultura atravesó los períodos de gobiernos constitucionales o dictatoriales, como aspecto propio de la época y de la relativa ausencia de espacios comerciales. Un elemento a destacar adicionalmente es que, si se produjo en los años '70 una cierta "decadencia" de las actividades culturales, la misma parece en rigor ocurrir ya con anterioridad a la dictadura de 1976. La tendencia a trascender la inscripción local de muchos artistas y literatos destacados llevó a un verdadero éxodo desde mediados de los años '60. Esa disposición estuvo probablemente ayudada por las restricciones de la intervención militar de 1966, las tensiones políticas en los ámbitos universitarios y eclesiales o la política editorial de El Litoral en algunos momentos ${ }^{\mathrm{v}}$. Ya se estaba produciendo desde antes un progresivo alejamiento de personalidades destacadas del ámbito de la cultura, continuada con los exilios del período 1974-1975 ${ }^{\text {vi }}$.

Por otra parte, no hay que menospreciar la violencia política anterior al 24 de marzo de 1976 y sobre todo el clima de represión paraestatal inaugurado en 1974. En ese período se produjo en el ámbito del Ministerio de Educación y Cultura de la Provincia un proceso de depuración ideológica mediante la aplicación de la Ley de Prescindibilidad. Lo mismo ocurrió en la Universidad Nacional del Litoral, donde hubo numerosas cesantías y cancelaciones de contratos de personal docente desde octubre de 1974 hasta diciembre de 1975. De acuerdo con testimonios como el de Julio Beltzer, en esa época joven director de teatro:

A partir del año 74 comienza la etapa en la que varios de los realizadores de esa época empiezan a borrarse. (...) es como si hubiese un vacío desde Isabelita [María Estela Martínez de Perón] hasta el 78 que son los años más bravos de refugio en las casas (BELTZER en GÓMEZ, 2007, p. 1-2).

\begin{tabular}{l|l} 
Revista RBBA & Revista Binacional Brasil Argentina
\end{tabular} 

DEMOCRÁTICA

Con seguridad es necesario estudiar en profundidad ese momento de "clausura" cultural más allá de las evocaciones de los participantes. Pero inicialmente podemos apreciar las complejidades de las relaciones de poder entretejidas en el espacio local, con la recomposición del campo cultural en el período dictatorial en una etapa de relativa "normalización" de la dictadura. Esto es, cuando ya había pasado el período en el cual se desarrolló el plan de exterminio de opositores y entre tanto no se había producido un resquebrajamiento del poder militar, visible éste no sólo tras la Guerra de Malvinas sino incluso desde 1981, con el incremento de la conflictividad laboral y la crisis inflacionaria.

Para el momento de la etapa central de la dictadura (c. 1979-1981) es factible apreciar un conjunto de espacios culturales con relativa autonomía. Por ejemplo, con el funcionamiento del Coro Universitario Independiente, la Agrupación Coral-Instrumental Ars Nova, el Mozarteum local, el conjunto instrumental-vocal Bach, que reunía a estudiantes del Liceo Municipal y del Instituto Superior de Música ${ }^{\text {vii }}$. También con el funcionamiento de salas de exposición de artes plásticas distintas de los espacios oficiales, que hacia el período mencionado tuvieron una suerte de expansión ${ }^{\text {viii }}$. O señaladamente con las proyecciones de películas en el Cine Club Santa Fe y en menor medida con el cine Núcleo Joven ${ }^{\text {ix }}$. Aunque con ciertas limitaciones y censuras, cada vez menos evidentes, había asimismo un amplio circuito de venta y difusión de libros que se reseñaban en la prensa local.

La mayor parte de la información disponible sobre esas actividades y los debates artísticos recogidos en el período por el diario El Litoral muestran discusiones ceñidas al problema de la representación. Con seguridad, los contenidos no eran materia sobre lo cual se pudiera trabajar libremente. Un plástico como Domingo Sahda se recordaría luego bloqueado en su producción hacia 1976-77, reiniciando sus exposiciones con obras de corte simbolista hacia 1980 y desarrollando obras más explícitas y crudas desde 1981 (Sahda en GÓMEZ, 2007, p. 6-7). Otro como Federico Aymá se fue del país en 1979, agobiado por la imposibilidad de trabajar ${ }^{\mathrm{x}}$.

Sin embargo, hubo también espacios en los que se podía aludir a los contenidos y es de notar que un medio esencialmente conservador como El Litoral cobijó a un amplio sector de la crítica artística y de la producción literaria local, en ocasiones meramente formalista, pero en otras capaz de sugerir la identificación de problemas sociales y políticos ${ }^{\mathrm{xi}}$. Con todo, el lenguaje utilizado fue muchas veces críptico y se correspondía con la necesidad de leer "entre líneas" lo que podía publicarse. 
El campo cultural santafesino se presentaba entonces como un espacio complejo y plural, en el cual un conjunto muy heterogéneo de agencias y agentes intervenían en sentidos disímiles ${ }^{\mathrm{xii}}$. Lejos de la interpretación que marcaba una suerte de "apagón cultural" provocado por la represión y la censura dictatoriales a lo largo de todo el período ${ }^{x i i i}$, el ámbito de las artes y la literatura tenía un dinamismo particular dentro de los márgenes del gobierno autoritario. Pero a su vez, es también discutible que pueda hablarse sin más de una "resistencia" en torno a las actividades culturales, ya que es difícil encontrar bajo el imperio del terror de Estado un modelo de artistas o intelectuales que asumirían una función crítica con la intención clara asumida individual o colectivamente- de responder a los imperativos de una lucha.

La historiografía sobre las actitudes sociales frente a las dictaduras ha mostrado la existencia de amplias “zonas grises” y la inextricable combinación de consensos y disidencias (LVOVICH, 2009 y 2013). Para el uso de una categoría como "resistencia cultural" se debería empezar por admitir que existieron muy variados posicionamientos, y que los matices y las contradicciones no fueron accidentales sino parte de las mismas relaciones de poder. En ese sentido, es destacable la propuesta de Federico Iglesias (2016: cap. 1) de aplicar esa noción a ciertas actividades culturales bajo la última dictadura argentina por asimilación al concepto de Resistenz propuesto por Martin Broszat ${ }^{\mathrm{xiv}}$. Este supondría un universo de formas de rechazo parcial y limitado o de disidencia inorgánica, expresadas en una pluralidad de actitudes pasivas, acciones espontáneas, sentimientos y actitudes.

Para el caso santafesino quizás sea posible, a partir de la descripción de algunos episodios del subcampo del teatro, proponer interpretaciones de acciones que claramente no se presentarían como "resistentes" en el sentido fuerte de la palabra castellana, pero que muestran discrepancias, disidencias o puntos de ruptura de un espacio social que distaba de ser controlado con mano de hierro por las agencias dictatoriales. 

DEMOCRÁTICA

\section{Teatro independiente y comunidad teatral en la etapa central de la dictadura ${ }^{\mathrm{xv}}$}

En la ciudad de Santa Fe no existía para el período dictatorial un verdadero "teatro comercial" y los espectáculos que tenían ese cariz provenían de Buenos Aires y en menor medida de Rosario. El espacio teatral autóctono estaba ocupado en su casi totalidad por el "teatro independiente"xvi , si bien algunos elencos conseguían cierta recaudación ${ }^{\text {xvii }}$.

Los grupos de teatro actuantes en la ciudad de Santa Fe y su zona de influencia fueron varios durante el período central de la dictadura, involucraron a una gran cantidad de personas, tuvieron una muy variada gama de estilos y repercusiones disímiles. Brindar un panorama completo de la actividad en teatro y teatro de títeres sería excesivamente extenso y contendría con seguridad falencias ${ }^{x v i i i}$. Lo que es claro es que se había producido una retracción del espacio de exhibición hacia el inicio de la dictadura: frente a nueve obras independientes estrenadas en 1974 y ocho en 1975, sólo hubo tres en 1976. Ya para 1977 anticipando el momento expresado en los recuerdos de Beltzer - se recuperó la actividad teatral con puestas en escena de variados matices.

Una característica distintiva del período dictatorial -además de la lógica limitación de las obras y de los autores, entre los que ya no se encontrarían temáticas o identidades políticas imposibles de representar en el contexto autoritario- fue la retracción de la participación oficial en el ámbito teatral en comparación con los intentos del gobierno constitucional anterior. En 1976 se clausuraron el Taller Laboratorio y la Comedia Provincial, y en 1978 el Elenco Estable de Muñecos ${ }^{x i x}$. En ese último año el gobierno de la Provincia creó un "Teatro para la Salud", destinado a apoyar la educación sanitaria en las escuelas (SCHENQUER, 2016), y tuvo continuidad el Teatro del Liceo Municipal, cuyos montajes estaban a cargo de directores que se desempeñaban en el espacio independiente.

Ya en 1977 hubo más actividad teatral independiente que bajo el gobierno constitucional, lo que probablemente pueda interpretarse como una compensación frente a la clausura de los espacios cobijados por instituciones oficiales. Adicionalmente, se observa una modificación de los grupos teatrales, con la progresiva aparición de nuevos nucleamientos y la ampliación del espacio del teatro en la localidad. De las experiencias de 1973-1975 sólo se discontinuó la del Grupo Alpha, dirigido por Ricardo Ahumada, si bien de ello no debe inferirse que las personas que lo integraban no continuaran en otros ámbitos ${ }^{\mathrm{xx}}$. 
Hay que destacar también la frecuente circulación de actores, directores y escenógrafos entre un grupo y otro, o las escisiones y combinaciones. Una misma persona podía participar de varios espacios teatrales al mismo tiempo y no era infrecuente la colaboración entre diversos agrupamientos. La extensión de la práctica de directores invitados también enfatizaba esa circulación. Incluso resulta dificultoso definir un elenco o grupo teatral concreto en una puesta en escena, ya que aparecen con distinta denominación en los registros, en función de esa dinámica de entrecruzamientos y escisiones ${ }^{\mathrm{xxi}}$.

Podría postularse también la participación de los distintos dramaturgos y actores en una cierta cultura de clase, no solo por su pertenencia a las clases medias en un sentido amplio, sino también por el predominio de estudios superiores orientados a las artes y las letras o a disciplinas vinculadas. Y como suele suceder en ámbitos de experiencias compartidas, pueden reconstruirse distintas relaciones familiares o amorosas.

Teniendo en cuenta esos aspectos, podría pensarse que más allá de las evidentes diferencias entre uno u otro grupo sobre la forma de hacer teatro o la selección de obras, existía en la zona santafesina una verdadera comunidad teatral. Enfatizar las diferencias entre unos y otros elencos puede ser discutible, pese a lo cual también es conveniente marcar elecciones divergentes.

De las puestas en escena del período 1979-1981, resulta relevante reseñar algunas. Un grupo dedicado al teatro infantil cuya actividad atravesó todos los setenta y continuó en los años siguientes fue Los Mamelli, que se había constituido en 1972. Tuvo formaciones cambiantes $^{\mathrm{xxii}} \mathrm{y}$ su director fue Hugo Maggi, que dirigió también otros emprendimientos mayormente presentados en la Sala Marechal del Teatro Municipal ${ }^{x x i i i}$. En 1980 llegó a la Sala Mayor con Inodoro Pereyra, el renegau, obra basada en textos del rosarino Roberto Fontanarrosa que ya había estrenado en 1974 y que se continuaría presentando en temporadas subsiguientes con mucho éxito. Para 1983 montaría el espectáculo musical Canciones para Mirar de María Elena Walsh, mientras que el director Raúl Galoppe haría lo mismo con Decadencia Divina de Mary Canca. Entretanto, en julio de 1981 Roberto Lemes -actor en Inodoro Pereyra...- dirigió Abran cancha, que aquí viene Don Quijote de la Mancha, de Adela Basch ${ }^{\mathrm{xxiv}}$. 

DEMOCRÁTICA

Por su parte, entre los años de 1978 y 1980 el Núcleo Teatral Talía dirigido por Osvaldo Neyra - con antecedentes bajo la denominación Cuatro Tablas -, presentó tres comedias siguiendo una secuencia de géneros: La cantante calva de Eugene Ionesco (humor absurdo), El médico a palos de Moliére (humor satírico) y Cuento de la hora de acostarse de Sean O’Casey (humor burlesco), que obtuvieron críticas amables, pero no entusiastas en El Litoral. Aunque en estos casos se trataba de clásicos, tanto en ellos como en los anteriores las obras apuntaban más al divertimento. Si bien podían presentar aspectos disruptivos desde la perspectiva de un medio social mayormente conservador, no se apreciaría en ellas ninguna tendencia política opositora.

En circuitos diferentes se encontraban intérpretes como Carlos Thiel, quien desde inicios de la década de 1970 descollaba como docente, actor y titiritero. Thiel había tenido un papel relevante en el desarrollo de obras políticamente comprometidas, como Saco y Vanzetti de Rolli y Vicenzoni en 1973. Con su hermano Oscar y su hijo Guillermo, consiguió insertarse en un circuito de presentaciones nacionales e internacionales ${ }^{\mathrm{xxv}}$. Hay que destacar que el teatro de marionetas tenía un amplio desarrollo en Santa Fe, donde se contaban elencos independientes o con diversa inscripción institucional dirigidos a público infantil y adulto.

Cercano a ese grupo se encontraba Florentino Sánchez ${ }^{\mathrm{xxvi}}$, orientado al costumbrismo, pero también dado a los clásicos como etapa habitual del teatro independiente. Entre esos años desarrolló presentaciones en vecinales, entidades benéficas y otras instituciones barriales santafesinas. En 1981 presentó Informe para una academia, en versión de María Rosa Oliver del texto de Franz Kafka, y una obra de títeres llamada Historia y divertimento infantil para un actor y cuatro títeres con el sello de Teatro del Cisne, ambas en la Casa del Maestro, local de la Asociación del Magisterio de Santa Fe. Otros teatros de títeres del período fueron los grupos El Pájaro Azul, dirigido por Matías Rodríguez, El Retablo de las Maravillas, de Oscar Caamaño y Cristina Pepe, y Bicho Colorao, conducido por Jorge Delconte.

Por fin, existía también un amplio espacio de teatro vocacional asociado a entidades educativas. De la gran cantidad de presentaciones del período es relevante destacar, por su autoría y dirección, el estreno de la obra Obando, de Edgardo Pesante, en el Colegio Nuestra Señora de Guadalupe. Su director fue Alberto Estrubia y a tenor de la información periodística el montaje necesitó un gran apoyo de otros grupos.

De los elencos de teatro independiente del período, algunos se caracterizaron por puestas en escenas novedosas y hasta transgresoras. El primero fue el Teatro Llanura -cuyo \begin{tabular}{l|l} 
Revista RBBA & Revista Binacional Brasil Argentina
\end{tabular} 
referente era (y es en la actualidad) Jorge Ricci-, formado a inicios de los años '70, luego de una serie de experiencias compartidas por varios de sus fundadores ${ }^{\text {xxvii }}$. Para 1975 el Equipo Llanura abrió una escuela de actores y técnica teatral en la Biblioteca "Mariano Moreno". En ese momento integraban el Equipo el mismo Ricci, Jorge Conti, Cristina Telesco, Ricardo Gandini, Rubén Varela, Pete Cánaves, Carlos Falco, María Delia Fernández, Estela Curi y Marina Vázquez ${ }^{\mathrm{xxviii}}$. Con esa escuela las perspectivas de Ricci y Conti tuvieron un innegable impacto en el medio teatral santafesino. Por ese espacio pasaron muchos de los integrantes de los elencos que se fueron formando a posteriori y el Llanura sufrió varias escisiones e incorporaciones en 1975-1977, que su conductor recuerda hoy asociadas a las discusiones sobre las opciones teatrales o incluso a "problemas de polleras" (RICCI, 2014b) y no respecto de diferencias políticas.

Junto con Los Mamelli, el Llanura fue el único elenco que no dejó de presentar obras de manera continua ${ }^{\mathrm{xxix}}$. Paralelamente, Ricci dirigió en esos años piezas del Teatro del Liceo Municipal. Experimentó en persona las ambivalencias del poder dictatorial, ya que fue cesanteado en un cargo público, pero no en otro que mantuvo sin inconvenientes ${ }^{\mathrm{xxx}}$. Entre el final de los años '70 e inicios de los ' 80 , estaba buscando elaborar un lenguaje teatral y desarrollar contenidos que no fueran mera imitación de los grupos de Buenos Aires ${ }^{\text {xxxi }}$. Un intento en ese sentido fue la obra Zapatones, que recurriendo a formas propias del circo presentaba la historia de un cómico acompañado por un chico tramoyista interpretado por María Rosa Peiffer. Se estrenó en junio de 1980 en la Sala Marechal ${ }^{\text {xxxii }}$, la recepción por el público "fue fantástica" (Pfeiffer, 2017) y recibió críticas muy elogiosas respecto de todas sus facetas: “Deliberado ejercicio para actor y acompañante, 'Zapatones' concita el desafío que Ricci-autor ha lanzado a Ricci-actor. Haber salido airoso de su propia propuesta es tal vez la mejor gratificación de su carrera"xxxiii.

Por su parte, el Grupo de Actores dirigido por Antonio Germano y con la asistencia de Ricardo Ahumada, osciló en esos años entre las representaciones tragicómicas en la tradición argentina del grotesco y el sainete, y los dramas de autores clásicos. En 1979 estrenaron El abanico de Venecia, de Juan Carlos Ghiano, y al siguiente Cómico", una pieza de Germano dedicada a la trayectoria artística de Pablo Podestá. Tanto esas como las obras de 1981 a 1983 
se presentaron en el Teatro de la Biblioteca Moreno ${ }^{\text {xxxiv }}$, mientras Germano sería también mentor del Grupo Estable de Rafaela y del que se formó en la Alianza Francesa de Santa Fe.

Para 1980 cobraban relieve también dos nucleamientos en los que tenían participación destacada Jorge Conti y Ricardo Gandini: Nuestro Teatro, que presentó en la sala de la Asociación Unione e Benevolenza La Biunda de Carlos Carlino, con dirección de Conti y Juan Carlos Rodríguez F., y el Teatro Arena donde Gandini montó El Cine de Enrique Wernicke. Este último fue director de la Escuela de Actores del Arena, en cuya sala propia daba clases de historia del teatro Conti y ensayaban otros elencos.

En este repaso del teatro independiente también corresponden señalarse las obras dirigidas por Julio Beltzer, más joven que la mayoría de los anteriores y que recién culminaría sus estudios de Letras en este período. Con el Teatro del Actor y la colaboración de Daniel Machado había presentado en 1978 Final de Partida de Samuel Beckett y en 1980 En Altamar de Slawomir Mrozek.

Para el período central de la dictadura, entonces, el peso de la actividad teatral era muy fuerte en el ámbito local y regional. Los distintos grupos llegaron a conformar una Coordinadora que organizó desde 1979 Muestras Nacionales en el Municipal de Santa Fe, en vínculo con distintas entidades como la Sociedad de Bioquímicos, la Federación Argentina de Trabajadores de Teatro Agremiados, la Fundación Arcien y distintas casas comerciales que prestaban su apoyo. Pese a esa clara inserción en el contexto institucional santafesino, la Coordinadora de Teatro no dejaba de suscitar suspicacias en la Comunidad de Inteligencia del Área 212, que vigilaba sus acciones ${ }^{\mathrm{xxx}}$. Los concurrentes, cuyo perfil estudiantil no pasaba desapercibido para las entidades policiales, eran minuciosamente contabilizados ${ }^{\mathrm{xxxvi}}$. Aunque ninguna de las piezas teatrales fuera en rigor "teatro político", muchas de ellas criticaban la moral dominante o el ejercicio del poder y sus intenciones no escapaban a la "Comunidad de Inteligencia".

El caso del titiritero y actor Matías Rodríguez es un buen ejemplo de cómo individuos o grupos podían moverse en los intersticios del poder dictatorial, cuyas agencias podían restringir y habilitar las actividades teatrales de manera contradictoria. La Compañía El Pájaro Azul había dado su primera función el 20 de octubre de 1975 en Ceres y en ese mismo año Rodríguez había participado en la formación del Teatro de Títeres Municipal de Santa Fe. Su ficha de antecedentes lo calificaba como "de ideas de izquierda", "marxista" y "zurdo", y vinculado a un grupo -en ese momento El Retablo de las Maravillas- en el que se detectaba 
una "ex-colaboradora de la BDT Montoneros"xxxvii . Pero como el mismo informe destacaba, Rodríguez contaba con cierto apoyo de la Dirección de Cultura de la Municipalidad de Santa Fe, que en 1977 y 1978 había solventado un Festival Nacional de Teatros de Muñecos y que en 1981 organizaría un curso sobre "El juego dramático en la educación” a cargo de su padre, el conocido actor y titiritero Rubén "Chiry” Rodríguez. Matías fue despedido del teatro de títeres de Santa Fe en 1979, pero hacia 1978-1979 formó el Teatro de Títeres Municipal "Trigal” de la vecina ciudad de Esperanza, donde también organizó encuentros nacionales de marionetistas. Por fin, en mayo de 1980 dictó un curso sobre "El títere y el niño" auspiciado por la Asociación de Psicólogos de Santa Fe ${ }^{\mathrm{xxxviii}}$.

Pero tal vez el cénit de la extrañeza o indignación de las autoridades policiales teniendo en cuenta el tenor de sus informes- haya venido dado por un viaje emprendido por la Compañía. En 1980 El Pájaro Azul concurrió al Festival Mundial de Muñecos en Washington en carácter de delegación por Argentina, y aprovechando el viaje realizó una gira por Colombia, Ecuador y la provincia argentina de Mendoza con tres espectáculos que se presentarían durante los años 1980 y 1981 en Santa Fe ${ }^{\text {xxxix }}$. En la nota publicada en el vespertino local, los titiriteros decían "Viajamos por nuestra cuenta, pero los organizadores de la muestra nos darán alojamiento..., facilitándonos el ingreso a todos los espectáculos” ${ }^{\text {xl }}$. Sin embargo, la Dirección General de Informaciones de la Provincia destacaba que Rodríguez había gestionado el apoyo económico del agregado militar de la embajada argentina ${ }^{x l i}$. Quizá la preocupación de esa repartición creciera cuando en 1981 El Pájaro Azul pasó a presentarse regularmente en El Mundo de María Azucena, programa televisivo infantil del Canal 13.

Esas situaciones dúplices de inserción institucional y vigilancia policial muestran la complejidad de las relaciones sociales y de poder en el campo cultural. Mientras algunas agencias estatales controlaban la actividad teatral y calificaban como potencialmente peligrosos a distintos agentes individuales o colectivos, otras reparticiones les facilitaban la presentación de sus obras. Es precisamente el caso del Teatro Municipal, que bajo la dirección de Jorge Terpin dio una amplia acogida a los grupos independientes ${ }^{\text {xlii. }}$. Varios elencos se encontraban inscriptos en una situación ambivalente: por un lado, expresando ideas que podían ser consideradas disidentes o hasta "subversivas" por los poderes estatales, y por el 

DEMOCRÁTICA

otro integrándose en un complejo de acciones y colaboraciones con las autoridades dictatoriales. Tal vez, la situación descripta podría ser interpretada como "transicional".

\section{Una tragedia clásica y un drama argentino en los inicios de la transición}

Es posible afirmar que la transición desde la dictadura militar a un gobierno constitucional comenzó hacia 1981. La reconfiguración del movimiento obrero y el incremento de la conflictividad social, la deslegitimación producida por la debacle económica -visible ya desde el año anterior-, la ocupación de los espacios públicos por el movimiento por los derechos humanos, el entierro definitivo de los planes de articular un movimiento político adicto y la formación de la Multipartidaria con los partidos parlamentarios, marcaron ya la imposibilidad del poder militar de mantener el orden y controlar su herencia.

Para ese momento el Grupo de Actores había reemplazado al Llanura en el uso de la Sala Moreno, tradicionalmente afecta a acoger actividades progresistas. Antonio Germano había logrado una gran repercusión con Cómico y se orientaba claramente a una recuperación de las tradiciones teatrales criollas. Sin embargo, una de sus obras más recordadas de este período fue en rigor un clásico: Macbeth, de William Shakespeare ${ }^{\text {xliii }}$.

A la distancia, Germano rememoró Macbeth como una apuesta políticamente comprometida, estimando que una obra sobre un personaje que usurpa la corona y es vencido por los deudos de aquellos a quienes ha asesinado, no podía ser asumida en ese momento como un entretenimiento normal. Recordó particularmente que el arzobispo de Santa Fe, monseñor Vicente Zaspe, asistió acompañado de un conjunto de clérigos y seminaristas, en lo que fue entendido como un acto tendiente a proteger a los intérpretes (Germano en SCHNEIDER y BUCCI, 2013, passim).

La repercusión de Macbeth en el diario local no dejó entrever ninguna lectura en clave crítica. Si las hubo en ese momento, debieron quedar limitadas a discusiones en la comunidad teatral. Inversamente, la obra fue elogiada por sus características formales. El crítico habitual de El Litoral la calificó como una "lograda" y “descarnada versión” y destacó que su montaje era "un empeño que no tiene precedentes en nuestro medio..." "xliv. Tanto esa como otras notas destacaron el rigor del vestuario y las espadas utilizadas por un elenco entonces muy joven.

Las posteriores presentaciones del Grupo de Actores tuvieron también gran éxito de público, pero no alcanzaron la repercusión pública del clásico isabelino. Y, sobre todo, no 
fueron recordadas luego como cesuras en el espacio teatral santafesino. Tal vez Macbeth comparta con un montaje del Llanura la posibilidad de ser pensadas como obras de la transición, de la misma manera que Cómico y Zapatones habían sido obras centradas en la introspección y la auto-reflexión.

De las muchas obras presentadas por el Teatro Llanura durante la dictadura, El Jorobadito fue sin dudas la que más repercusión parece haber logrado y la que supuso la consolidación del Equipo en el ámbito santafesino, la afirmación de su presencia en la más importante ciudad de Rosario y el inicio de su proyección nacional. Fue realizada sobre el texto de Roberto Arlt, según la versión de Rodolfo Aldasoro ${ }^{x l v}$. Se estrenó en 1981 en Santa Fe y al año siguiente participó de la segunda edición de Teatro Abierto, en un contexto de clara oposición a la dictadura militar y junto con piezas notoriamente políticas ${ }^{\mathrm{xlvi}}$.

Desde un inicio, la obra tuvo un cierto halo de desafío a las autoridades dictatoriales y el público parecía esperar algo que permitiera pensar metafóricamente el momento social y político. Según Ricci, "Había una frase de El Jorobadito que le decía el padre,... que dice algo de los militares. Y me acuerdo que cuando se decía ese texto corría una ventisca..." (RICCI, 2014b). Sin embargo, él mismo destacó que la obra fue elegida solamente por la posibilidad de poner en juego cuestiones formales y de contenido que resultaran inquietantes, sin un trasfondo político.

La actriz principal fue la joven María Rosa Pfeiffer, que se había radicado en Santa Fe hacia 1976 para estudiar teatro y artes visuales, proveniente del pequeño pueblo vecino de Humbolt. Pfeiffer se formó en el Teatro del Actor, pero su debut fue con el Llanura en Zapatones $^{\mathrm{xlvii}}$. Para ella, los aspectos más disruptivos de El Jorobadito eran relativos a la puesta en cuestión de las representaciones de género y a la crudeza de algunas escenas. Rememorando ese estreno más de treinta años después, pensaba que el elemento más urticante era que el actor que representaba a una mujer mayor lo hiciera sin afeitarse los bigotes (Pfeiffer en SCHNEIDER y BUCCI, 2013: 25). El actor en cuestión era Juan Carlos Rodríguez F, oriundo de la cercana localidad de Recreo y como Pfeiffer egresado de la Escuela de Artes Visuales “Juan Mantovani”, pero de una generación mayor ya que era coetáneo de Riccirlviii. 

DEMOCRÁTICA

Es posible que la escena más señalada fuera una en la cual Bruza y Pfeiffer interpretaban una situación onírica de contenido sexual. Si bien no había desnudos -algo inusitado en el teatro de la época más allá de la dominación militar- la escena y los gestos fueron muy explícitos. Comentando con un amplio auditorio esa sección de la obra, hoy todavía destacada por lo "jugada” en el ámbito cultural santafesino, María Rosa recordaba que en una de las presentaciones se encontraba su madre entre el público y que “...se había clavado las uñas en las rodillas y se las dejó marcadas..." (Pfeiffer en SCHNEIDER y BUCCI, 2013, p. 25).

La rememoración de esas acciones puede plantear nuevos interrogantes. En un contexto represivo, ¿cómo era posible que se presentaran esas escenas, o qué grados de libertad tenían dramaturgos, directores y actores para representar qué obras? Antonio Germano refirió que "a veces una comisión de censura nos visitaba en los ensayos" y comenta que en esas ocasiones se variaban un poco las obras (Germano en SCHNEIDER y BUCCI, 2013, p. 173). Pero Jorge Ricci no recordó haber sufrido censura previa de sus obras, e incluso planteó: "Me parece a mí que no estábamos siendo observados. A lo mejor éramos observados y yo no lo sé” (Ricci, 2014b).

La percepción de Ricci era errónea. Las actividades teatrales eran parte de los "medios de comunicación" relevados sistemáticamente por las agencias dictatoriales ${ }^{\text {xlix }}$, sus hacedores -como él mismo- identificados y sus espectadores computados y caracterizados. Pero como se ha destacado más arriba, en el complejo de agencias y agentes intervinientes en la producción y puesta en escena de las obras puede apreciarse una gran complejidad de relaciones. No se trata de una sociedad sometida completamente a la dominación dictatorial mediante el uso de la fuerza, sino de una serie de espacios articulados, públicos y privados, plurales ellos mismos, en los cuales los agentes individuales y colectivos tenían ciertos márgenes de decisión y acción.

¿Qué postular entonces respecto de la posibilidad de una "resistencia cultural”? ¿Podríamos encontrar algún papel particular del teatro en Santa Fe en la transición a la democracia? 


\section{Interpretaciones: a) situación del teatro santafesino y transición política}

Si el debate sobre la "resistencia cultural" puede ser definido en los términos expresados más arriba, es claro que hubo en el campo cultural santafesino una multitud de posicionamientos y actitudes que no podemos evaluar en términos de resistencia organizada al poder dictatorial, pero tampoco de clara integración en la lógica de las agencias represivas. Ello hace que muchas actividades culturales puedan ser leídas como oposiciones eventuales, propuestas disidentes o simples divergencias de lo que supuestamente - y cabe enfatizar el "supuestamente" - las autoridades dictatoriales podían esperar de la población.

Los desarrollos teatrales y hasta la dinámica del campo cultural santafesino en su conjunto pueden ser interpretados como producto de una interacción conflictiva entre agentes y agencias. Las autoridades nacionales, provinciales y municipales, las agencias estatales policiales, culturales y educativas, los elencos teatrales, los directores y los productores, los grupos de afinidad y parentesco, los colectivos difusos como "el estudiantado" o "la comunidad teatral". Todos esos agentes colectivos suponían asimismo agentes individuales que se posicionaban en un espacio social determinado y que adoptaban estrategias de distinto nivel, fuera para reproducir su vida cotidiana, fuera para conseguir la satisfacción de deseos o intereses determinados. De ahí que el resultado de sus acciones no fuera la plasmación de una u otra intención, sino un conjunto de consecuencias no intentadas. Sin embargo, esta hipótesis tan evidente necesita ser pensada específicamente respecto del teatro santafesino y la transición política.

Los controles dictatoriales, y en particular la censura, no sólo alcanzaron a las estructuras fundamentales de la producción cinematográfica, editorial o musical. Los ámbitos culturales, entendidos en el sentido de espacios artísticos y literarios distintos de los medios masivos de comunicación, también fueron escenario de políticas restrictivas. Pero quizás en esos casos la dialéctica entre represión y resistencias fue más compleja y dejaba más posibilidades de acción disidente. A medida que se fueron eliminando las resistencias efectivas de las organizaciones político-militares y que el ejercicio de una violencia acrecentada daba paso a la "normalidad" autoritaria, se incrementó el control sobre asociaciones intermedias, grupos culturales y sectores socioprofesionales que se entendían 

DEMOCRÁTICA

proclives para la prédica "comunista" o "subversiva". Existían por tanto políticas de vigilancia $y$, si bien el exterminio o el encarcelamiento prolongado no formaban efectivamente parte del horizonte represivo con el cual se podían encontrar quienes transgredían las normas o tendencias vigentes en el campo cultural, la posibilidad de presiones, cesantías o prohibiciones era constante.

En las reconstrucciones que personas como Julio Beltzer, Domingo Sahda, Juan Carlos Arch o Antonio Germano realizaron del período treinta años después, latieron las ideas de un terror instalado, de la posibilidad de la violencia física represiva, del exilio o prisión de muchos allegados y de los contactos cara a cara como refugio durante el peor momento de la dictadura. Pero también aparecieron en esos discursos nociones sobre lo contradictorio que resultaba que autores expresamente prohibidos pudieran ser representados sin mayores problemas, o que - como en el caso de Ricci - una persona pudiera ser cesada de un empleo público y mantener otro.

Todas esas situaciones se vinculan con el problema de lo que se podía decir públicamente, sea en los medios de comunicación, en los púlpitos o en los teatros. Y en todas esas oportunidades se producían equilibrios inestables en las relaciones de fuerza y también entre las lógicas del constreñimiento y la habilitación, de los límites y los intereses y deseos, o si se quiere de la represión y las resistencias. Estas últimas se produjeron en los límites de la normalidad de las tareas de inteligencia, las políticas estatales o incluso la cultura dominante en una ciudad de provincias, pero a la vez estuvieron sobredeterminadas por la presencia o la rememoración de la violencia extrema propia del régimen político dictatorial ${ }^{1}$.

Esas situaciones en parte paradojales -como la coexistencia de la represión y la habilitación - y en parte sobredeterminadas por acontecimientos que no estaban presentes en ese momento -como la desaparición forzada o el exilio-, ponen en cuestión la posibilidad de un relato sobre esas pujas respecto de lo decible o representable en el arte y la literatura basado sólo en la interacción. Al fin de cuentas, la interpretación de una interacción conflictiva parece asentarse firmemente en la capacidad de acción de los agentes, pero subrepticiamente instala como pauta de explicación el funcionamiento de las esferas e instituciones en las cuales se enmarca tal interacción.

Al decir de Beltzer "al ser el teatro una cuestión más metafórica se podía hablar de ciertas cosas" (Beltzer en GÓMEZ, 2007); mientras que para Ricci "el teatro de arte que hacíamos nosotros era una cosa de cofradía y entonces evidentemente no alcanzaba a la 
preocupación de [las autoridades por] lo que podía ser la música popular, el cine" (RICCI, 2014b). Y esas facetas habrían habilitado entonces el desarrollo de expresiones artísticas destinadas a públicos reducidos, que podían (o se esforzaban por) leer las obras en términos políticos. Pero ambas lecturas, con ser más o menos correctas, ponen entre paréntesis el hecho de que las actividades teatrales santafesinas se inscribían en la "institución arte"li.

Tanto en las experiencias del Teatro Llanura como en las del Grupo de Actores y los demás colectivos teatrales, no se puso en dudas la relativa autonomía del arte respecto de una praxis cotidiana. La vida social - propia y ajena - no se veía impactada en lo sustancial por las actividades artísticas de esos agrupamientos, sino que se seguía encontrando regulada por las lógicas y dinámicas de un capitalismo periférico en la esfera económica y de un gobierno dictatorial que dominaba una esfera política en la cual tenían participación otros agentes ora más consensuales, ora más disidentes. Adicionalmente, el marco de la vida cotidiana y del campo político santafesinos podría ser descripto en términos más conservadores ${ }^{\text {lii }}$, como parte de una gubernamentalidad autoritaria que limitaba más las conductas más que en otros espacios local-regionales. ${ }^{\text {liii }}$

La forma de integración general de las experiencias teatrales santafesinas remite a la noción de "posvanguardia" de Peter Bürger, en tanto hay un aprovechamiento de los procedimientos vanguardistas con fines artísticos, pero se abandona la pretensión antiartística y el postulado de la eliminación de la distancia entre el arte y la vida cotidiana. Desde esa perspectiva, el teatro santafesino se incluyó plenamente en la institución arte -tendencia por otra parte absolutamente lógica no sólo en términos de una situación particular de dominación dictatorial, sino de la imposibilidad de redireccionamiento del arte hacia la praxis en el sistema capitalista- ${ }^{\text {liv }}$. El hecho de que en el contexto de una obra de teatro "se pudieran decir ciertas cosas" no generaba de por sí efectos sobre el exterior de la comunidad artística reunida en torno a esa representación y ni siquiera sobre la praxis cotidiana de esa misma comunidad. Hasta podría especularse que el mayor margen de libertad en la representación teatral podía operar como compensación de las restricciones políticas o comunicacionales ${ }^{\mathrm{lv}}$.

Pero es también importante recordar que decir esas cosas o no, no era una cuestión menor en un contexto de fuertes restricciones políticas y culturales. Paralelamente, la conformación de grupos que hegemonizarían el desarrollo teatral santafesino en la década de 
1970 y muy especialmente con las divisiones producidas durante la dictadura, colaboró con la constitución de formas de producción novedosas que modificaban la institución arte. Si el teatro santafesino -como otros espacios de producción cultural coetáneos- no pudo poner en cuestión la autonomía de la obra en un momento en el cual muchos de sus practicantes pensaban que había que "hacer algo" frente a la dictadura, no es menos cierto que no cayó en la concepción esteticista. Por un lado, sus formas no respondían puramente a los imperativos de una esfera autónoma, sino que estaban tensionadas por el clima socio-político. Por el otro, el contenido no dejó de ser un elemento de importancia.

En vez de conseguirse respuestas firmes, se abren entonces nuevos problemas. Si ninguno de los agentes podía hacer estrictamente "lo que quería" de tal manera que Matías Rodríguez no podía montar las obras que deseaba y la Dirección de Informaciones no podía prohibirle actuar, ello no era un puro efecto de sus intereses cruzados sino también de un equilibrio social. Podría decirse que la "institución teatro" adoptó en Santa Fe formas de desarrollo que supusieron relaciones equilibradas -en el sentido de formas más o menos estables y fijadas a un juego de restricciones y compensaciones- con otras instituciones y especialmente con las agencias estatales. Y como siempre, en ese juego de equilibrios aparecían pequeñas fisuras, aspectos de contenido -entrelazados o no con el problema de la forma- que iban más allá de los límites del equilibrio.

Es quizás en la detección de esas fisuras donde podemos encontrar la contribución de la comunidad teatral y de la institución teatro al proceso de transición política. Hubo con seguridad obras teatrales que colaboraron en la construcción de una cultura disidente y por tanto en la erosión de los límites del poder dictatorial -aunque a veces la disidencia no fuera en particular con respecto a las autoridades de la dictadura, sino con relación a una gubernamentalidad autoritaria local. Se abriría entonces otro problema de interpretación: ¿dónde podrían encontrarse esas fisuras?

\section{Intepretaciones: b) transición teatral y subjetividades disidentes}

Tal vez puedan pensarse obras como algunas de las referidas este texto en tanto fisuras del equilibrio socio-político o espacios de afirmación de una subjetividad disidente. Los montajes de Cómico y Zapatones parecen responder a un estadio de reflexión sobre la propia práctica actoral por parte de sus autores e intérpretes - Germano y Ricci, respectivamente -. Desde esa perspectiva podían incluir una u otra línea de crítica social en sus guiones, pero 
probablemente puedan ser pensadas como ejercicios previos a la posibilidad de un contenido con ribetes socio-políticos, necesarias para identificar el lugar que se ocupa en la sociedad y las tensiones que atraviesan a los propios productores de cultura.

En cambio, Macbeth y El Jorobadito ya suponen opciones distintas. Según Germano, una elección así se basaba en que "no podíamos hacer un teatro de entretenimiento... Nos resultaba terrible no decir cosas. Por lo menos, las que nos animábamos a decir" (Germano en SCHNEIDER y BUCCI, 2013, p. 173). Inversamente, Ricci defendería la idea de una opción motivada puramente en las posibilidades expresivas del texto.

Macbeth no era en rigor un símbolo del poder dictatorial. Era en todo caso una alegoría y la posibilidad de su lectura en clave disidente era menor. Sin embargo, fue concebida luego como momento de afirmación de una resistencia y a tenor del comentario sobre la asistencia del arzobispo Zazpe pudo ser pensada de esa manera. Rockyfeller en el lejano oeste era ya una sátira de la cultura y los agentes que se entendían el aval imperialista del gobierno de turno, y como tal más explícita en el nivel del contenido. Esa mayor tendencia a la explicitación de un contenido crítico parece congruente con la opción del grupo de Antonio Germano por formas teatrales "populares" y justificaría su visión de una práctica cultural resistente: tanto forma como contenido resultarían expresión de una intención crítica al interior de la institución arte y contra el poder autoritario.

Frente a esa constatación, aparece un interrogante puntual. ¿Por qué entonces fue $E l$ Jorobadito la obra que concitó tantas expectativas y la convocada para la segunda edición de Teatro Abierto en Buenos Aires, espacio claramente antidictatorial y contestatario?

Ricci presentó una lectura desde lo formal de esa obra, pero también apuntó cuestiones de contenido:

...si hay que buscar un puente entre novela y teatro arltiano, ese puente es el cuento y de todos los cuentos, El Jorobadito. ¿Por qué? Porque El Jorobadito es un personaje de una gran teatralidad, que condensa todo el mal y todo lo teatral. Y la historia que lo presenta está cargada de verdaderas situaciones dramáticas. (...) / No por casualidad este cuento ha sido teatralizado varias veces... /...el relator y el corcovado [son] dos caras de la misma moneda, dos marginales de esa clase media hipócrita que es el blanco preferido de Arlt (RICCI, 2005, p. 179). 
La opción de posvanguardia no carecía de elementos de una crítica de contenido y el posicionamiento de Ricci al interior del "teatro independiente" no era una cuestión meramente formal:

...el teatro independiente será también, aparte de teatro, un movimiento cultural que abrazará la clase media ilustrada con espectáculos, charlas, publicaciones, discursos y manifestaciones ante cada injusticia. (...) / ...los independientes (cultos, universitarios, pudientes), harán del teatro un quehacer didáctico... / (...) El teatro independiente se forjó en la búsqueda de la libertad de expresión, de opinión y de forma artística (RICCI, 2005, p. 165).

Haber sido parte del teatro independiente supondría entonces para Ricci también un cierto posicionamiento: "El independiente es aquel que sostiene la apuesta creativa (ética y estética) por sobre todos los otros avatares del oficio" (RICCI, 2005, p. 180). Y esa apuesta llevaba en El Jorobadito a la crítica de la "clase media hipócrita". Sin enunciar claramente una oposición política, Ricci expresaba quizás en ese momento una disidencia respecto de la realidad social mucho más clara que la de Macbeth o incluso que la del teatro costumbrista, de la manera en que su subjetividad le permitía hacerlo.

El correlato de la cuestión del contenido estaba en el problema de la forma. Desde esa perspectiva, la apuesta del Llanura aparece claramente rupturista no sólo con el modelo representado por el Grupo de Actores sino con la gubernamentalidad autoritaria en su conjunto. Probablemente El Jorobadito no sólo era una obra en el contexto de la transición, sino además una puesta en escena que daba cabal idea de lo que era un teatro en transición. Frente al cuidado del vestuario y las espadas de Macbeth, la obra arltiana se presentaba con un escenario que recordaba los postulados del "teatro pobre" de Grotowski. El Jorobadito no presentaba una escenografía, vestuario o técnicas complejas. Su montaje era muy austero y por el contrario ponía el acento en el trabajo y en el nivel actoral. Al decir de María Rosa Pfeiffer, la puesta en escena era transgresora y el involucramiento de los cuerpos de los actores muy profundo, al punto que desde la perspectiva de Reynoso Aldao era altamente criticable que anduvieran "tirándose por el suelo" (Pfeiffer, 2017). En otros términos, El Jorobadito representaba una transición hacia otras formas de estética teatral, que se enunciarían en la propuesta que Ricci presentaría poco después en Hacia un teatro salvaje. Y esa transición era además una transición generacional, ya que los directores y elencos que se 
afirmaban en la escena santafesina hacia finales de la dictadura e inicios del período democrático eran mayoritariamente distintos de los relevantes en los momentos anteriores.

La identificación de esas subjetividades disidentes - la expresa de Germano, la implícita de Ricci- nos retorna a la cuestión de cuáles fueron los agentes movilizados en torno a las actividades culturales críticas. En los excursos respecto de los acontecimientos reseñados se pueden encontrar algunas pistas. La formación de los integrantes de la comunidad teatral en el período central de la dictadura había pasado en gran medida por el Profesorado de Letras de la UNL y por el Profesorado en Artes Visuales de la Escuela Mantovani. Algunos otros provenían de estudios universitarios en disciplinas vinculadas. Podría especularse que esos lugares fueron espacios de construcción de subjetividades disidentes y que no estaban errados quienes pretendían controlarlos.

Las familias de procedencia de esos individuos "cultos, universitarios, pudientes", nos son todavía en gran medida desconocidas. En algunos casos podríamos identificar entre los padres de los artistas a comerciantes, prestadores de servicios, empleados públicos, docentes y hasta actores. Ellos mismos, y a veces sus progenitores, se incluían en el sector de servicios sociales y culturales de la clase de servicio - una fracción de importancia de las nuevas clases medias (MÜLLER, 1999). Tenían claramente "posiciones intermedias", de propiedad, de poder, de capacidades organizativas (WRIGHT, 1989), y un capital cultural específico. Eran, en definitiva, individuos procedentes de medios que les habían posibilitado formarse críticamente y que a su vez tenían desempeños socio-laborales que les facilitaban el ejercicio de la crítica.

Si reunimos dos conceptos planteados por separado por Jorge Ricci en el ensayo precitado, podemos suponer una fracción "ilustrada" de las clases medias opuesta a y crítica de otra fracción "hipócrita". Esa distinción es esencialmente una diferenciación cultural, aunque puede tener -como se aludió- una correspondencia socio-profesional. La Resistenz, captada específicamente con los matices de oposición, disidencia y divergencia, podría entonces ser entendida como un problema de tensiones al interior de las clases medias. La tensión entre aquellas facciones - mayoritarias - que asumieron con total naturalidad la continuidad de la vida cotidiana bajo la dictadura y aquellas otras - ubicadas principalmente en algunas instituciones o en los resquicios de la normalidad dictatorial- que aún sin verse 
directamente afectadas por la represión física sintieron que "algo había que hacer", pudieran o no decirlo en esos términos.

El rol de esos colectivos e individuos de las clases medias en el proceso de cambio institucional puede haber sido de un peso relativo, pero con seguridad no bastaron ni el rol del movimiento obrero ni el de las élites políticas para forzar la transición a un orden constitucional. El teatro santafesino estaba en transición desde una perspectiva generacional y estética. Quizás, haya también contribuido a la transición política.

\section{Referencias}

ALONSO, L. (2011) Luchas en plazas vacías de sueños. Movimiento de derechos humanos, orden local y acción antisistémica en Santa Fe, Rosario, Prohistoria.

ALONSO, L. (2015) "Redes y dimensiones espaciales en la movilización por los derechos humanos en Argentina", en Avances del Cesor V. XII, No 12, ISHIR - CONICET / UNR, en línea en http://web2.rosario-conicet.gov.ar/ojs/index.php/AvancesCesor.

ALONSO, L. (2016) "Sobre la vida (y a veces la muerte) en una ciudad provinciana. Terror de Estado, cultura represiva y resistencias en Santa Fe", en ÁGUILA, G.; GARAÑO, S. y SCATIZZA, P. (coords.), Represión estatal y violencia paraestatal en la historia reciente argentina: Nuevos abordajes a 40 años del golpe de Estado, Universidad Nacional de La Plata, 2016, en línea en http://www.libros.fahce.unlp.edu.ar/index.php/libros/catalog/book/63.

ALONSO, L. (2017) "Integración y resistencia en el campo cultural durante la última dictadura argentina: agentes colectivos, instituciones y acontecimientos en Santa Fe", ponencia ante el Segundo Congreso Internacional de la Asociación Latinoamericana e Ibérica de Historia Social, Buenos Aires.

ALONSO, L. y CITRONI, J. (2007) "Fiesta o ceremonia: carnavales y celebraciones oficiales en la zona santafesina antes y durante la última dictadura", en Actas del 2do. Congreso Regional de Historia e Historiografía, Universidad Nacional del Litoral, Santa Fe.

ALONSO, L. y CITRONI, J. (2008) "Intervenciones en la zona céntrica santafesina en época de dictadura: interacciones y conflictos", en Cuaderno Urbano $N^{\circ} 7$, Resistencia, Universidad Nacional del Nordeste / Universidad Nacional de La Plata.

ARCH, J. C. (2010) "Entrevista: El cineclub de Santa Fe según Juan Carlos Arch. Fenómeno de Resistencia Concreta”, en línea en http://cineclubesargentina.blogspot.com.ar/2010/01/elcineclub-de-santa-fe-segun-juan.html, consulta de febrero de 2017.

ARRESE, A. (1991) Formas no políticas de autoritarismo, Buenos Aires, Goethe-Institut. 
BOURDIEU, P. (1997) "Espacio social y espacio simbólico", en Razones prácticas, Barcelona, Anagrama.

BÜRGER, P. (2010) Teoría de la vanguardia, Buenos Aires, Las Cuarenta.

CAMPANA, J. (1999) Crónica sobre la política cultural de los gobiernos santafesinos (19201999), Rosario, Ediciones Culturales Santafesinas.

CITRONI, J. (2013) Modos de control del espacio urbano en un contexto de poder autoritario. Santa Fe, 1976-1981, tesina de Licenciatura en Historia, Universidad Nacional del Litoral, Santa Fe, 2013.

CORTÁZAR, J. (1984) Argentina: años de alambradas culturales, Barcelona, Muchnick.

DAYUB, Mauricio (s/f) Entrevista por Pablo Rodríguez Leirado en línea en Al Margen, http://www.almargen.com.ar/sitio/seccion/teatro/dayub/, consulta febrero de 2017.

GÓMEZ, J. (2007) La cultura santafesina durante los años de plomo. Producciones Especiales Diario El Litoral, Santa Fe.

GROTOWSKI, J. y otros, (1992) Hacia un teatro pobre, México, Siglo XXI.

GRÜNER, E. (1990-1991) "Política: ¿otro discurso sin sujeto? Aportes sobre el poder, la cultura y las identidades sociales", en El Cielo por Asalto, Buenos Aires.

GRÜNER, E. (2002) El fin de las pequeñas historias. De los estudios culturales al retorno (imposible) de lo trágico, Ed. Paidós, Buenos Aires, 2002.

HEREDIA, V. (2013) "Los Festivales Latinoamericanos de Teatro en Córdoba: escenarios de la democracia", ponencia ante las XIV Jornadas Interescuelas/Departamentos de Historia, Universidad Nacional de Cuyo, Mendoza, en línea en http://www.aacademica.org/000010/656 consulta de febrero de 2017.

IGLESIAS, F. (2016) Escritores, cultura y dictadura: El caso de la revista El ornitorrinco, tesis de la Maestría en Historia Contemporánea, Universidad Nacional de General Sarmiento, Los Polvorines, mimeo en línea en http://www.riehr.com.ar, consulta de febrero de 2017.

KARTUN, M. (2017) "De Teatro Abierto a Terrenal. «Todo teatro está basado en la hipótesis del enfrentamiento y la violencia»", entrevista por Verónica Perera y Maximiliano de La Puente, en Clepsidra. Revista Interdisciplinaria de Estudios sobre Memoria Vol. 4, No 7.

KERSHAW, I. (2004) La dictadura nazi. Problemas y perspectivas de interpretación, Buenos Aires, Siglo XXI. 

DEMOCRÁTICA

LVOVICH, D. (2013) “Actitudes sociales y dictaduras: Las historiografías española y argentina en perspectiva comparada", en ÁGUILA, G. y ALONSO, L. coords., Procesos represivos y actitudes sociales: entre la España franquista y las dictaduras del Cono Sur, Buenos Aires, Prometeo Libros.

LVOVICH, D. (2009) "Sistema político y actitudes sociales en la legitimación de la dictadura militar argentina (1976-1983)" en Ayer n 75, Madrid.

MARCHESE, C. (2009) "Los cineclubes en Argentina", en PLATINO, F. El Cine en Santa Fe, Santa Fe, Municipalidad de la Ciudad de Santa Fe.

MÜLLER, W. (1999) "La estructura de clases y el sistema de partidos", en Zona Abierta No 86/87, Madrid.

PELLETTIERI, O., dir. (2005) Historia del teatro argentino en las provincias, volumen I, Buenos Aires, Galerna.

PFEIFFER, María Rosa (2017) Entrevista personal por Luciano Alonso, Santa Fe, 11 de abril de 2017.

PISARELLO, M. V. (2013) "La "ilusión democrática" a través del diario El Litoral, 19831987”, en FALCHINI, A. y Alonso, L. eds., Los archivos de la memoria. Testimonios, historia y periodismo, Universidad Nacional del Litoral, Santa Fe.

RAMÍREZ, P. E. (2016) Arte y política en la ciudad de Santa Fe. Relaciones entre los artistas emergentes culturales santafesinos y el proceso general de radicalización política en los años 60, tesina de Licenciatura en Historia, Universidad Nacional del Litoral, Santa Fe, mimeo.

REYNOSO ALDAO, Jorge (2012) Entrevista por Darío Macor y Marcelino Maina, 16 de marzo de 2012, Santa Fe, Programa de Historia y Memoria de la Universidad Nacional del Litoral - Archivo de Historia Oral.

RICCI, J. (1986) Hacia un teatro salvaje, Cuadernos de Extensión Universitaria $N^{\circ}$ 6, Universidad Nacional del Litoral, Santa Fe.

RICCI, J. (2004) Entrevista "Hacer Teatro es un milagro", en Cuadernos del Picadero $\mathrm{N}^{\circ} 2$, Instituto Nacional del Teatro, Buenos Aires.

RICCI, J. (2005) "Momentos del Teatro Argentino (Ensayo Breve)", en Texturas N ${ }^{\circ}$ 3, Universidad Nacional del Litoral, Santa Fe.

RICCI, J. (2012) Entrevista "Jorge Ricci: "nada es totalmente nuevo en el teatro", en línea el 28 de noviembre de 2012 en http://www.lagaceta.com.ar/nota/522572/espectaculos/jorgericci-nada-totalmente-nuevo-teatro.html. 
RICCI, J. (2014a) Entrevista "Jorge Ricci, 40 años al frente del santafesino Grupo Llanura", en línea el 9 de junio de 2014 en http://www.telam.com.ar/notas/201406/66490-jorge-ricci40-anos-al-frente-del-santafesino-grupo-llanura.html.

RICCI, J. (2014b) Entrevista personal por Laura Schenquer y Luciano Alonso, Santa Fe, 30 de abril de 2014.

SAHDA, D. (1999) Creadores Santafesinos, Santa Fe, ed. del autor en fascículos con diversos auspicios, 1999 en adelante.

SCHENQUER, L. (2016) "Políticas culturales de la última dictadura de Argentina: construir consensos y cooptar a la población. El Teatro para la Salud de Santa Fe”, en Afuera. Estudios de crítica cultural.

SCHNEIDER, R. (2011) Entrevista "Roberto Schneider y el teatro", en línea el 6 de febrero de 2011 en http://agenciafe.com/wblogs/index.php?acc=ficha\&idart=89801).

SCHNEIDER, R. y BUCCI, V. Inventario del teatro independiente de Santa Fe, vol. II, Universidad Nacional del Litoral, Santa Fe, 2013.

SCHULTE-SASSE, J. "La vanguardia artística", en Realidad $\mathrm{N}^{\circ}$ 59, Universidad Centroamericana, San Salvador, 1997.

SPLENDIANI, I. Plástica santafesina. Renovaciones estéticas en los años '60, Santa Fe, María Muratore, 2011.

TAVERNA IRIGOYEN, J.M. "Federico Aymá. Canto y grito de un dibujante", en El Litoral, 29 de abril de 1988.

WRIGHT, E. O. “¿Qué tiene de media la clase media?”, en ROEMER, J. E. comp., El marxismo: una perspectiva analítica, México, Fondo de Cultura Económica, 1989.

ZAYAS DE LIMA, P. Diccionario de directores y escenógrafos del teatro argentino, Buenos Aires, Galerna, 1990.

\section{Notas}

\footnotetext{
" Centro de Estudios Sociales Interdisciplinarios del Litoral, Facultad de Humanidades y Ciencias de la Universidad Nacional del Litoral / Instituto de Humanidades y Ciencias Sociales del Litoral, Universidad Nacional del Litoral - Consejo Nacional de Investigaciones Científicas y Técnicas. Este artículo se inscribe en las actividades de los Proyectos de Investigación HAR2015-63657-P (MINECO/FEDER, UE) "Transiciones a la democracia en el sur de Europa y en América Latina: España, Portugal, Argentina y Chile" (UAB) y CAI+D
} 


\section{TEATRO EM TRANSIÇÃO. DRAMATURGIA, POLÍTICA E RELAÇÕES SOCIAIS EM SANTA FE (ARGENTINA), ENTRE A ÚLTIMA DITADURA E A TRANSIÇÃO DEMOCRÁTICA}

2016 (50120150100018LI - Secretaría de Ciencia y Técnica de la UNL) "Historia, memorias y representaciones del pasado reciente: espacios sociales, violencia política y derechos humanos".

${ }^{\text {i }}$ La ciudad de Santa Fe entra en Argentina en lo que se caracteriza como localidades de rango medio. La población del Departamento La Capital (ciudad de Santa Fe y localidades cercanas), con indicación del porcentaje sobre la población total de la provincia, fue de 312.427 habitantes en el Censo $1970(14,63 \%)$ y de 381.449 en el Censo 1980 (15,47 \%), siendo la población de la ciudad capital normalmente en torno a los tres cuartos del Departamento. Los departamentos del centro y norte de la provincia siempre estuvieron más vinculados a la capital de la provincia, mientras que los del sur giraron en torno a relaciones de diversa índole con la ciudad de Rosario, que siempre tuvo más del doble de población (Fuente: INDEC - Instituto Nacional de Estadísticas y Censos, http://www.indec.mecon.ar, consulta julio de 2011). Su zona céntrica, considerada tradicionalmente la más relevante en términos de poder político, nodos económicos y figuración social, apenas debilitada por las transformaciones territoriales de las décadas de 1990 y 2000 y aún hoy de gran peso para la configuración de las relaciones de poder locales / regionales, sería el espacio "entre bulevares": un ámbito de aproximadamente 20 a 25 cuadras de lado enmarcado por avenidas. Una definición más precisa de ese espacio en Alonso y Citroni, 2008.

ii Una caracterización desde el campo memorial de los vaivenes del diario El Litoral en Reynoso Aldao, 2012.

iii Sobre el calendario recurrente de actividades culturales y un detalle general hacia el período dictatorial véase Alonso, 2017. Los carnavales santafesinos tenían aún una participación multitudinaria, pero ya se registraba una cierta decadencia probablemente imputable a las transformaciones de las sensibilidades colectivas y el desarrollo de una cultura espectacular (ALONSO y CITRONI, 2007).

${ }^{i v}$ A propósito de la música clásica hay que señalar que en la esfera estatal se incluían una Orquesta Sinfónica, un Coro, una Banda Sinfónica de la Policía, distintas entidades orquestales y corales infanto-juveniles provinciales y municipales, y el Instituto Superior de Música de la UNL. En artes plásticas los espacios oficiales eran el Museo Provincial de Bellas Artes y el Museo Municipal de Artes Visuales, seguidos del Museo de la Costa de San José del Rincón, la Dirección General de Turismo de la Provincia, la Biblioteca Municipal de Santo Tomé y desde 1981 el Museo de la Ciudad de Santa Fe. En lo que hace a la literatura había distintos concursos de edición provinciales y municipales y en 1976 la gestión dictatorial creó el Fondo Editorial de la Provincia (y a tenor del relevamiento de Campana, 1999, la labor en la promoción de la literatura fue una de las líneas de acción más coherentes del gobierno dictatorial). Sobre los ámbitos educativos capaces de organizar actividades culturales, debe recordarse que en la Provincia de Santa Fe la educación puede ser pública o privada, pero la segunda está subsidiada por el Estado en una alta proporción. La dictadura de la "Revolución Argentina" de 1966-1973, estableció un sistema de sostenimiento y "garantía" de los establecimientos de gestión privada mediante la Ley Provincial Nº 6427 de 1968, todavía vigente.

v Ejemplos de estas tendencias fueron la dispersión del grupo de teatro municipal de Santo Tomé en 1966, la desarticulación del grupo de Extensión Universitaria formado en torno a Hugo Gola en los años '60 y el debilitamiento progresivo del Instituto de Cinematografía - preludio de su cierre por el último gobierno militar-, del cual ya se había alejado Fernando Birri. Una información bien trabajada sobre el período puede encontrarse en Ramírez, 2016.

vi Tomando como ejemplo el ámbito de las letras, en la década de 1960 habían migrado los escritores Francisco "Paco" Urondo, Eduardo Gudiño Kieffer y Juan José Saer. También se había alejado y luego fallecido Luis Gudiño Krámer, quien había sido secretario de redacción del diario El Litoral. Para 1975 se exilió el poeta Hugo Gola, despedido mucho antes del servicio de extensión universitaria.

${ }^{v i i}$ El Coro Universitario Independiente se había formado en 1976 y Ars Nova comenzó en 1978 a desarrollar regularmente sus "Primaveras Corales". Esos y otros espacios muestran bien la complejidad de las relaciones entre iniciativas independientes y agencias público-estatales.

viii Entre 1979 y 1981 se registraron exhibiciones en la Alianza Francesa, la Asociación Bancaria, el Salón de Canal 13, el Banco de Iguazú, el Centro Ferial de Artesanías Tradicionales, la Casa del Artista Plástico (de la Asociación de Artistas Plásticos Santafesinos), el Instituto del Litoral de Estudios Nacionales y las Galerías La 
Casona, Tacora, Cinter, Pieza Única, Arte Color, Privada de Arte, Finuart, Morello y Paracas, y otros espacios. Si bien sería muy extenso describir apenas un panorama de esas muestras, hay que señalar que varios de los artistas participantes habían sido parte de las renovaciones de la década anterior, cf. Splendiani, 2011. Una reseña de las personalidades más relevantes puede encontrarse en la serie de fascículos de Sahda, 1999.

ix No hubo producción fílmica durante el período en Santa Fe y la práctica del arte se limitó a talleres y cortos de ensayo. Hacia 1980 se habían producido cierres de salas cinematográficas en función de criterios comerciales y una tendencia a hacer otras nuevas más pequeñas. El Cine Club había sufrido distintos tipos de hostigamiento, pero no sólo pudo mantener su "parte ideológica", en expresión de su presidente, sino que incluso prosperó económicamente hasta adquirir en 1982 el cine América, con más butacas y comodidades que la sala del Cine Arte Chaplin. Véase Arch, 2010, y Marchese, 2009.

x Sobre Aymá véase Taverna Irigoyen, 1988 y el fascículo de Sahda correspondiente a la serie antes citada.

xi Véanse por ejemplo los debates sobre tres muestras simultáneas de Antonio Berni, que constituyeron probablemente el acontecimiento más importante en el ámbito de las artes plásticas durante toda la dictadura ( $E l$ Litoral 6, 9, 12, 15 y 18 de septiembre de 1980), la pluralidad de autores que publicaban en sus páginas literarias (que incluían escritores de filiación peronista como Florencia Lo Celso, Osvaldo Valli y Alejandro Damianovich y otros hasta comunista como Gastón Gori) o los debates sobre la censura cinematográfica (v. g. El Litoral, 5 de junio, 3 y 12 de agosto, 8 y 14 de septiembre de 1980, entre otros). También se publicaban notas sobre artistas y literatos extranjeros que eran conocidos por sus posiciones progresistas o izquierdistas. En su gran mayoría los textos no hacían referencia a las inclinaciones políticas, pero eran evidentes para el público ilustrado que las conocía. En otros casos, esas filiaciones eran explícitas e incluso se trataba en detalle sus peripecias exiliares (v. g. 26 de junio de 1980, p. 4, "Rafael Alberti: el 'poeta de la calle"”, por Julia Sáez-Angulo). Muchos de esos artículos estaban producidos por la agencia EFE y fechados en Madrid o en París, formando parte de la apertura política española. En 1982 el diario santafesino comenzó a editar un suplemento cultural mensual con el nombre de "La Comarca y el Mundo" que merecería de por sí un análisis detallado pero que escapa al objeto de este trabajo.

xii Una percepción general similar respecto del período de los años de 1960, con una preocupación por identificar los nodos de hegemonía en el campo, en Ramírez, 2016.

xiii V. g., la visión de un arrasamiento cultural y de la capacidad autoritaria de modelar la psicología de las masas se refleja en Cortázar, 1984 y en algunas de las contribuciones reunidas en Arrese, 1991.

${ }^{\text {xiv }}$ De acuerdo con Kershaw (2004: cap. 8), la noción de Widerstand -traducible directamente por "resistencia"estaría restringida a las conductas de rechazo fundamental y organizado al régimen, en tanto que la de Resistenz permitiría hablar de un amplio abanico de actitudes.

${ }^{\mathrm{xv}}$ La información de esta sección sobre los agrupamientos, obras presentadas y datos personales proviene del Diario El Litoral, de los libros de Zayas de Lima, 1990; Pellettieri, 2005 y Schneider y Bucci, 2013; de los sitios web Alternativa Teatral, Teatro del Pueblo y Asociación de Trabajadores del Estado -ATE Santa Fe, Sección "Artistas Santafesinos" (http://www.alternativateatral.com, http://www.teatrodelpueblo.org.ar y http://www.ate.org, respectivamente); de blogs, linkedin y facebook personales (María Rosa Pfeiffer, Osvaldo Pettinari, Jorge Ricci, Julio Beltzer, Oscar Caamaño, Fabián Rodríguez, Mauricio Dayub), de los obituarios a Juan Carlos Rodríguez F, Matías Rodríguez y Jorge Delconte (Diario El Litoral, http://www.lt10.com.ar y sumilares); de las memorias de Florentino Sánchez en línea en www.sepaargentina.com.ar; de folletos de obras de teatro depositados en el AMPSF (Archivo de la Memoria de la Provincia de Santa Fe) y de distintas entrevistas a Roberto Schneider (2011), a Jorge Ricci (2004, 2012 y 2014a) y entrevista personal por Laura Schenquer y Luciano Alonso, Santa Fe, 30 de abril de 2014, y a María Rosa Pfeiffer, entrevista personal por Luciano Alonso, Santa Fe, 11 de abril de 2017. Todas las consultas de sitios web son de febrero de 2017. En tanto no se han encontrado mayores contradicciones en la triangulación de las fuentes, a los fines de no interrumpir la narración se remitirá a las referencias correspondientes sólo cuando se realicen citas textuales o que merezcan destacarse.

\begin{tabular}{l|l} 
Revista RBBA & Revista Binacional Brasil Argentina
\end{tabular} 
xvi El teatro independiente argentino se llamó así, desde sus comienzos entre los años de 1930 y 1950, porque no dependía de instancias comerciales o institucionales. Su emergencia rompió con la distinción entre profesionales y vocacionales, estableciendo una nueva diferenciación entre teatro comercial y teatro de arte. Desde los años '70 y sobre todo con posterioridad a la transición democrática, se podría hablar de un teatro neoindependiente, cuya cualidad distintiva es la profesionalización y una constante experimentación o ausencia de formas consagradas de representación (RICCI, 2005).

xvii Es discutible intentar clasificar a todos los elencos en la distinción oficial / comercial / independiente. Por ejemplo, Hugo y Osvaldo Maggi presentaron en Santa Fe una serie de obras muy exitosas -entre ellas, algunas de las que se aluden más adelante- y en gran medida pudieron sostenerse económicamente con esos desempeños. Pero calificar su actividad de "comercial" asimilándola a las empresas teatrales porteñas es difícilmente sostenible.

xviii Una reseña de las obras de cierto relieve presentadas en Santa Fe se encuentra en Pellettieri, 2005: 444 a 447, en una cronología realizada por Jorge Ricci. Hay que destacar que tiene algunas ausencias de importancia teniendo en cuenta otros registros.

xix Es interesante destacar que la clausura de esos espacios no fue abrupta. Por ejemplo, para 1977 se renovó el Elenco de Muñecos con personal contratado, que no fue convocado ya al año siguiente (PFEIFFER, 2017).

${ }^{x x}$ Ricardo Ahumada no fue incluido en las cesantías de 1974-1976 en la UNL y siguió desempeñándose como profesor de varias materias de arte y literatura en la Escuela Universitaria del Profesorado. En el período 19791981 aparece vinculado al Grupo de Actores, como se verá más adelante.

${ }^{x x i}$ Por ejemplo, Osvaldo Neyra y un grupo variable aparecieron en montajes bajo la denominación de Cuatro Tablas. Posteriormente, bajo ese nombre se montaron obras con la dirección de Roberto Lemes y Neyra conformó el Grupo Talía, aunque luego también apareció en el Teatro de la Casa del Maestro. La llanura estremecida, que sería una de las obras iniciales del Teatro Llanura, escrita por Jorge Ricci y con dirección de Ricardo Gandini, también aparece registrada como propia del Teatro Mandala. Por otra parte, la Cooperativa Teatral de Maggi no aparece mencionada con ese nombre con posterioridad a 1977, pero Ricci la identifica con la reposición de Inodoro Pereyra en 1980 (en PELLETTIERI, 2005: 445).

xxii Por la dilatada experiencia de Los Mamelli, claramente intergeneracional, pasaron Hugo y Osvaldo Maggi, Raúl Farías, Paco Hase, Mónica Bono, Cocho Maragno, Lina Volpogni, Adriana Cornú, Eduardo Pascucci, Carlos Deb, Ricardo Llusá, Mónica Moreno, Silvana Montemurri, Maga Malvicino, Pati Malvicino, Nelly Giscafré, Patricia Moreno, Mario Culasso, José Luis Volpogni, Silvia Paredes, Alicia Belucci, Alicia Naput, Marta Coutaz, Susana Fuentes, Carlos Thiel, Osvaldo Pettinari, Juan Carlos Rodríguez, Fernando Collados, Martín Sosa, Benjamín Sosa y Agustín Posentini (http://gobierno.santafe.gov.ar/prensa, noticia del lunes 15 de agosto de 2011 - 150811s11.htm, consulta de febrero de 2017). Entre sus integrantes de los años '70 se contaron Cornú, Pascucci, Morello y Montemurri. Para la temporada 1979 sus integrantes eran Volpogni, Pati y Maga Malvicino, Moreno, Chochó Maragno y Culasso, y en la temporada 1981 Moreno, Culasso, Llusá, Deb y Luis Maragno, este último no registrado en el listado antes citado.

xxiii La Sala "Leopoldo Marechal" del Teatro Municipal "10 de Mayo" de Santa Fe, recibió ese nombre bajo el gobierno constitucional de 1973-1976. Está ubicada sobre un costado del edificio y tiene una capacidad de aproximadamente 200 butacas, muy inferior a las 800 de la Sala Mayor y por ello más apropiada para obras de teatro independiente. Una tercera sala, más pequeña y en los altos de la misma ala del teatro, también fue usada para representaciones teatrales en el período bajo análisis.

xxiv Esa obra contó con las actuaciones de Silvia Bertaina, Dady Brieva y Babi Gutiérrez, que se presentaron bajo el nombre de Las Cuatro Tablas.

xxv A propósito de una presentación de Carlos y Guillermo en el Centro Cultural San Martín de la ciudad de Buenos Aires, Oscar destacaba la articulación entre actores y muñecos como una novedad en el medio teatral, que luego sería seguida por otros titiriteros santafesinos. EL Litoral, 4 de septiembre de 1980, p. 12.

xxvi Sánchez era Profesor de Artes Visuales, titiritero y actor. Se identificaba con el peronismo de izquierdas y había sido expulsado de la Escuela de Artes Visuales en 1969, cuando era presidente del Centro de Estudiantes. 
xxvii Jorge Ricci había vivido siempre en Santo Tomé y Santa Fe, iniciando sus actividades teatrales en un elenco de la municipalidad de la primera ciudad que se desarticuló tras el golpe de Estado de 1966. Estudió Letras en la UNL junto con su esposa, María Delia Fernández y participó del Grupo 67. Si bien la obra que cimentó su fama en el medio local fue el montaje de Woyzeck de Georg Buchner, en la Sala Marechal, el Equipo Llanura ya había presentado El nitrógeno de Obaldía y La llanura estremecida de Ricci en 1972, y repetiría su éxito en 1974 con Ubú Rey de Jarry y en 1975 De Chéjov con humor, sobre textos del autor ruso.

xxviii De los nombrados, los primeros cuatro figuraban en distintas publicaciones como profesores o directivos de la escuela de teatro, v. g. en El Litoral, 2 y 8 de febrero de 1975, pp. 10 y 7 respectivamente. Las asignaturas iniciales fueron Formación del Actor, Teoría Teatral, Historia Social del Teatro y Expresión Corporal, las dos primeras a cargo de Ricci, la tercera de Conti y la cuarta de Telesco. Muchos de ellos habían estudiado Letras y en el caso de Falco Arquitectura. Al menos Fernández, Vázquez, Ricci y Falco estaban emparentados.

xxix En 1976 montaron Escorial de Michel de Ghelderode, en 1977 El Debut de la Piba de Roberto Cayol y Mustafá de Armando Discépolo, en 1978 Sueño de Juventud de Ricci y en 1979 Lágrimas y Sonrisas, de González, Castellano y Ricci, estas dos últimas en colaboración con equipos rosarinos.

xxx Para la Comunidad de Inteligencia Ricci era potencialmente peligroso incluso mucho después del golpe de Estado, ya que se destacaban sus "relaciones con elementos del PST" (Partido Socialista de los Trabajares) y anteriores vinculaciones con otros grupos de izquierda. Informe del Departamento de Inteligencia 122 del Ejército del 19 de abril de 1979 sobre la Biblioteca Moreno e informe de igual fuente del 29 de agosto de 1980 sobre antecedentes de grupos de cine y teatro en respuesta a requerimiento de la Dirección General de Informaciones de la Provincia (AMPSF). Su esposa María Delia si fue cesada en todos sus cargos.

xxxi Ya las experiencias del Grupo 67 y del primer Llanura habían estado atravesadas por la influencia de los postulados del "teatro pobre" de Jerzy Grotowski y suponían un alejamiento de los cánones del momento (Grotowski y otros, 1992; el original inglés es de 1968 y el artículo que da nombre al volumen de 1965). Hacia 1984 Ricci escribiría una serie de reflexiones criticando el carácter imitativo del teatro del interior respecto de las experiencias de Buenos Aires y planteando las posibilidades de construcción de una poética grotesca que entremezcle humor y drama para hablar "de cosas que tienen que ver con el paisaje en el que nosotros nos movemos" (RICCI, 1986).

xxxii Con dirección invitada de Roberto Lemes, música de Osvaldo y Hugo Maggi, Carlos Gianni y Eduardo Segal. Los demás aspectos serían cubiertos por los técnicos del teatro Municipal "siempre eficientes y de buena voluntad", según declaraciones de los integrantes del Llanura en El Litoral, 6 de junio de 1980, p. 11. Ricci diría más adelante: "Tomé una serie de elementos del circo tradicional pero como excusa para reflexionar sobre la problemática del actor que evidentemente me persigue como una obsesión... Por eso Zapatones inicia esa cuestión un tanto existencial que se mantiene a través del tiempo" (RICCI, 2004; según el entrevistador, Ricci consideraría a esa obra como "la prehistoria" de la laureada Actores de Provincia, que interpretaría más adelante con Rafael Bruza).

xxxiii El Litoral, 12 de junio de 1980, p. 13, nota firmada por “R. A.” (Jorge Reynoso Aldao).

${ }^{x x x i v}$ Macbeth de William Shakespeare en 1981, en 1982 Rockyfeller en el lejano oeste de Rene de Obaldía y en 1983 Todos eran mis hijos de Arthur Miller.

xxxv Nota del Jefe de Departamento de Inteligencia 122 del Ejército Luis Alberto González, del 20 de mayo de 1980, convocando a reunión del 3er. Nivel de la Comunidad de Inteligencia (AMPSF).

xxxvi Por ejemplo, en 1979 se registraron 2.859 personas para la asistencia a diez obras, según informe sin firma sobre la Muestra Nacional de Teatros realizada del 7 al 14 de octubre de 1979, Dirección General de Informaciones de la Provincia de Santa Fe, en respuesta al Mensaje 32181 del 16 de octubre de 1979 (AMPSF). xxxvii Informe sin firma sobre Matías Pablo Rodríguez Sempólis, Dirección General de Informaciones de la Provincia de Santa Fe, 20 de mayo de 1980 (AMPSF). 
xxxviii Eso pudo motivar una mayor mirada de las agencias represivas sobre esa entidad. El anuncio del curso apareció en El Litoral el 11 de mayo de 1980. El día 20 la Jefatura de Departamento de Inteligencia 122 incluía a la Asociación de Psicólogos en el temario de la reunión del 3er. Nivel de la Comunidad de Inteligencia.

xxxix El World Puppetry Festival de ese año fue un evento patrocinado por el Kennedy Center, el Instituto Smithsoniano y la UNESCO. Para esa ocasión Rodríguez presentó un espectáculo de muñecos de guante y varilla integrado por ocho romances juglarescos españoles. En el resto de la gira se presentaron los espectáculos Señor Títere y Galera Verde. La Compañía estaba integrada en ese momento por Matías Rodríguez, Fabián Rodríguez, Carlos Falco, Marina Vázquez y los esperancinos Osvaldo Klug y Ethel Ranallo Cabe recordar aquí que el matrimonio Falco-Vázquez había participado del Teatro Llanura, en tanto que Fabián Rodríguez era hermano de Matías y estudiante de Letras en la UNL.

${ }^{x l}$ El Litoral, 9 de junio de 1980, p. 12.

xli Informe sin firma sobre Matías Pablo Rodríguez Sempólis, op. cit.

xlii Esa actitud amplia fue más tarde reconocida por directores como Ricci, para quien la de Terpin fue "tal vez una de las mejores gestiones que hubo en el teatro" (entrevista personal, op. cit.) o Germano, quien declararía que "nos abrió la puerta, cuando las puertas estaban cerradas para nosotros" (Germano en SCHNEIDER y BUCCI, 2013: 67). Terpin también jugaba un papel importante en la difusión de las actividades culturales, concurriendo a entrevistas en El Litoral y seguramente también en las radios locales. La secretaria del Teatro Municipal era en esos momentos una persona íntimamente vinculada a la actividad teatral: Silvana Montemurri (PFEIFFER, 2017).

xliii La pieza aparece mencionada en las fuentes alternativamente como Macbeth, La tragedia de Macbeth y La tragedia de Lady Macbeth. Lo cierto es que Germano -que había estudiado literatura- armó un texto especial para la ocasión utilizando tres traducciones diferentes de la obra original. Actuaron el mismo Germano, Mary Canca, Mauricio Dayub, Roberto Schneider, Rubén Casella, Mónica Laurencena, Cristina Pagnanelli, Osvaldo Pettinari. La escenografía fue de Juan Lazzarini y la música de Ricardo Pérez Miró. Pettinari, que había egresado en 1977 de la Escuela de Artes Visuales de Santa Fe, tuvo también a su cargo cuestiones de escenografía y vestuario. Es de señalar que la obra supuso la primera actuación -y en un papel relevante- de Roberto Schneider, quien estudiaba Letras en la UNL y luego sería un reconocido crítico teatral. Ambas especialidades -artes y letras- eran a su vez un campo de formación compartido por los demás miembros del equipo, salvo Dayub que era estudiante de Ciencias Económicas y a quién sus compañeros recomendaban que no se dedicara a la actuación porque se "iba a morir de hambre" (DAYUB, s/f).

${ }^{\text {xliv }}$ El Litoral, 11 de junio de 1981, p. 12, nota firmada por "R. A." (Jorge Reynoso Aldao).

${ }^{x l v} E l$ Jorobadito fue dirigida por Jorge Ricci, contó con la actuación de Rafael Bruzza, Rubén Gattino, Daniel Machado, María Rosa Pfeiffer, Juan Carlos Rodríguez y Humberto Torres. El vestuario y la escenografía fueron créditos del Equipo Llanura, la iluminación de Miguel Novello y la música de Jorge Molina.

xlvi De acuerdo con Mauricio Kartun, en 1981 Teatro Abierto había reunido obras "que andaban dando vueltas y que se habían armado sin la necesidad de tener que dar una opinión sobre la dictadura", pero para 1982 "todos querían, de alguna manera, «decir algo» y se ponían enfáticos en su «versión monstruosa del Falcon»". De esa manera se "Abrió un concurso para definir quién escribía la voz más rotunda en un momento en que todos estábamos «calientes como una pipa»" (KARTUN, 2017, p. 143).

xlvii Pfeiffer había realizado cursos sobre manejo de títeres y su aplicación en la pedagogía con Domingo Sahda gracias a quien participó en 1977 del Elenco Estable de Muñecos de la Provincia-y de literatura y plástica en la Universidad Católica de Santa Fe, pero su formación más importante fue como Profesora Superior de Artes Visuales Especializada en Pintura. En el período central de la dictadura comenzaba a desarrollar actividades en el ámbito de las bellas artes: fue quien hizo el diseño de programa y el maquillaje para Zapatones, en 1981 dictó un curso sobre "Escultores santafesinos" en el Museo Municipal de Artes Visuales y realizó un mural en la Iglesia de San Antonio, y en 1983 participaría con dibujos en una muestra de artistas santafesinos.

xlviii El "Flaco" Rodríguez había estudiado en el taller de Carlos Thiel y del Teatro de Arte pasó luego al Llanura, aunque en paralelo trabajaba con Conti en Nuestro Teatro. Además de a la dramaturgia, se dedicó a la plástica y a la docencia. 
xlix Por ejemplo, Parte SIDE 7982 del 27 de agosto de 1979 a Delegaciones Provinciales, que solicitaba información, entre otros, de los teatros existentes con indicación de propietarios de las salas, tipo de obras, autores, actores, responsables, "ideología", etcétera (AMPSF).

${ }^{1}$ Reitero aquí argumentos mejor desarrollados en Alonso, 2016.

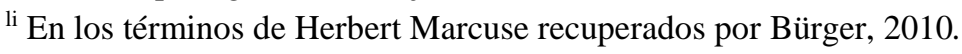

lii Esa es incluso la lectura actual de Pfeiffer, quien en 1984 se sintió impactada por el Festival Latinoamericano de Teatro de Córdoba al punto de decidir mudarse a esa ciudad, cuyo espacio cultural y teatral era "mucho más combativo" (PFEIFFER, 2017). Sobre estos festivales véase Heredia, 2013.

liii He propuesto una adecuación del concepto foucaultiano de "gubernamentalidad" y su aplicación a la zona santafesina en Alonso, 2011; una clarificación de las articulaciones entre distintas dimensiones y la consideración del nivel de la gubernamentalidad en Alonso, 2015.

liv En términos de Bürger, la superación de la dicotomía entre arte y vida “...no ha ocurrido y quizás, tampoco pueda ocurrir en la sociedad burguesa, a menos que se dé bajo la forma de una falsa superación del arte autónomo [como en la literatura de divertimiento o en la estética de la mercancía]" (BÜRGER, 2010, p. 76).

lv “...es posible que las contradicciones entre modos de expresión y de acción no sean experimentadas como tales, mientras el marco institucional los mantenga separados. Un modo radical de expresión, pensamiento o acción en el terreno estético puede simplemente compensar su ausencia en otras esferas de la vida. Una actividad artística formalmente radical, en otras palabras, puede perfectamente caber dentro de la función compensatoria de lo estético en la sociedad" (SCHULTE-SASSE, 1997, p.545.).

\section{Sobre o Autor}

Luciano Alonso. Doctor en Humanidades con mención en Historia. Trabaja en la Facultad de Humanidades y Ciencias de la Universidad Nacional del Litoral, donde está a cargo de la cátedra de Historia Social y de otras asignaturas de historia y sociología. Actualmente es allí director del Centro de Estudios Sociales Interdisciplinarios del Litoral y participa del Instituto de Humanidades y Ciencias Sociales del Litoral (CONICETUNL). Sus investigaciones de los últimos años tienen que ver con la movilización por los derechos humanos, los procesos represivos latinoamericanos y las formas de resistencia cultural ante gobiernos autoritarios. Dirige en la UNL un proyecto de investigación sobre Historia, memoria y representaciones del pasado reciente y participa de dos grupos de investigación internacionales: uno de la Pontifícia Universidade Católica do Rio Grande do Sul y otro de la Universidad Autónoma de Barcelona. Correo Electrónico: lpjalonso8@ gmail.com 